\title{
Antibiotic prescribing in UK out-of-hours primary care services: a realist-informed scoping review of training and guidelines for healthcare professionals
}

\author{
Paula Gomes Alves ${ }^{1}$, Gail Hayward ${ }^{2}$, Geraldine Leydon ${ }^{3}$, Rebecca Barnes ${ }^{4}$, \\ Catherine Woods ${ }^{3}$, Joseph Webb ${ }^{4}$, Matthew Booker ${ }^{4}$, Helen Ireton ${ }^{5}$, Sue Latter ${ }^{3}$, \\ Paul Little ${ }^{3}$, Michael Moore ${ }^{3}$, Clare-Louise Nicholls ${ }^{6}$, Fiona Stevenson ${ }^{7 *}$ \\ ${ }^{1}$ University of Greenwich, London, UK; ${ }^{2}$ University of Oxford, Oxford, UK; ${ }^{3}$ University \\ of Southampton, Southampton, UK; ${ }^{4}$ University of Bristol, Bristol, UK; ${ }^{5}$ Registered \\ Nurse, Solent NHS Trust, Portsmouth, UK; ${ }^{6}$ Registered Nurse, BrisDoc Heathcare \\ Services, Bristol, UK; ${ }^{7}$ University College London, London, UK
}

*For correspondence: $f$. stevenson@ucl.ac.uk

Competing interest: The authors declare that no competing interests exist.

Received: 03 November 2020 Accepted: 17 December 2020 Published: 28 April 2021

(C)This article is Open Access: CC BY license (https://creativecommons.org/licenses/by/4.0/)

Author Keywords: prescribing, guidelines, community care, anti-bacterial agents, after-hours care, drug resistance, bacterial

Copyright (C) 2021, The Authors; DOI:10.3399/BJGPO.2020.0167

\begin{abstract}
Background: Antibiotic overuse has contributed to antimicrobial resistance, which is a global public health problem. In the UK, despite the fall in rates of antibiotic prescription since 2013, prescribing levels remain high in comparison with other European countries. Prescribing in out-of-hours $(\mathrm{OOH})$ care provides unique challenges for prudent prescribing, for which professionals may not be prepared.

Aim: To explore the guidance available to professionals on prescribing antibiotics for common infections in $\mathrm{OOH}$ primary care within the UK, with a focus on training resources, guidelines, and clinical recommendations.

Design \& setting: A realist-informed scoping review of peer-reviewed articles and grey literature.

Method: The review focused on antibiotic prescribing $\mathrm{OOH}$ (for example, clinical guidelines and training videos). General prescribing guidance was searched whenever $\mathrm{OOH}$-focused resources were unavailable. Electronic databases and websites of national agencies and professional societies were searched following Preferred Reporting Items for Systematic Reviews and Meta-Analyses (PRISMA) standards. Findings were organised according to realist review components, that is, mechanisms, contexts, and outcomes.

Results: In total, 46 clinical guidelines and eight training resources were identified. Clinical guidelines targeted adults and children, and included recommendations on prescription strategy, spectrum of the antibiotic prescribed, communication with patients, treatment duration, and decision-making processes. No clinical guidelines or training resources focusing specifically on $\mathrm{OOH}$ were found.

Conclusion: The results highlight a lack of knowledge about whether existing resources address the challenges faced by $\mathrm{OOH}$ antibiotic prescribers. Further research is needed to explore the training needs of $\mathrm{OOH}$ health professionals, and whether further $\mathrm{OOH}$-focused resources need to be developed given the rates of antibiotic prescribing in this setting.
\end{abstract}

\section{How this fit in}

A higher proportion of antibiotics are prescribed in $\mathrm{OOH}$ primary care services, which may contribute to antibiotic resistance. Prescribing $\mathrm{OOH}$ has additional challenges for health professionals, including managing patient anxiety and professionals being unfamiliar with patients' prior medical history and 
social circumstances. There is a lack of specific guidance for health professionals prescribing antibiotics in $\mathrm{OOH}$ primary care services. Providing evidence-based training targeting health professionals working $\mathrm{OOH}$ may increase prudent antibiotic prescribing.

\section{Introduction}

Overuse and inappropriate prescribing of antibiotics is a worldwide public health concern as a major driver of antibiotic resistance. ${ }^{1}$ In the UK, 81\% of all antibiotic prescriptions in 2017 were in primary care, ${ }^{2}$ including general practice and other community settings such as $\mathrm{OOH}$ services. Although antibiotic prescribing rates in general practice in the UK have fallen since 2013, rates of prescribing in $\mathrm{OOH}$ settings are increasing. ${ }^{3}$ Approximately, $15 \%$ of $\mathrm{OOH}$ consultations result in an antibiotic prescription, with suggestions this could represent a partial shift of antibiotic prescribing from in-hours to $\mathrm{OOH}$ primary care. ${ }^{4}$ Prescribing of antibiotics $\mathrm{OOH}$ in the UK is high in relation to other European countries such as the Netherlands. ${ }^{5}$ Moreover, a substantial proportion of UK prescriptions have been reported as not clinically warranted, ${ }^{6,7}$ with research indicating that if the level of prescribing in the UK decreased there would not be an increase in complications. ${ }^{8}$

Providing training in health care is key to improving quality of care and reducing prescription rates. ${ }^{9}$ In 2013, a multinational European study (which included the UK), showed that internet-based communication training plus $\mathrm{C}$-reactive protein testing in general practice could reduce antibiotic prescribing for respiratory tract infections (RTIs) by $15 \% .{ }^{10}$ In another study, communication skills training reduced antibiotic prescribing in $27 \%$ of cases. ${ }^{11}$ More recently, in a study conducted in Belgium, antibiotic prescriptions for RTls dropped by $12 \%$ following online training on prudent antibiotic use and prescribing $i^{12}$ and in the US, a clinical trial demonstrated that providing professionals with training on communication strategies and individualised prescribing feedback, decreased antibiotic prescribing for RTIs by $11 \%$ and produced a sustained reduction of $7 \%$ at follow-up. ${ }^{13}$

However, little is known about how existing clinical guidelines and training materials account for the unique challenges of prescribing $\mathrm{OOH}$, which include professionals being unfamiliar with the patient's medical history, the urgency of complaints, and patient anxiety and expectations. ${ }^{14}$ The goal of this study was to explore the guidance available to health professionals on prescribing antibiotics for common infections in $\mathrm{OOH}$ primary care within the UK. The review aimed to identify research evidence, training resources, guidelines, and clinical recommendations relating to antibiotic prescribing in $\mathrm{OOH}$ primary care in the UK. General antibiotic prescribing guidance was searched whenever $\mathrm{OOH}$-focused guidance was unavailable.

\section{Method}

The scoping review followed PRISMA guidelines. ${ }^{15}$ The review was part of a larger mixed-methods observational study exploring how professionals and patients (and/or caregivers) communicate about common infections and their treatment OOH (the OPEN Project; https://www.spcr.nihr.ac.uk/projects/ 414-understanding-antibiotic-prescribing-patterns-in-out-of-hours-ooh-primary-care).

For this review, the authors wanted to go beyond a traditional systematic review, which focuses on whether an intervention works or not, to instead explore the mechanisms underlying antibiotic prescribing in $\mathrm{OOH}$ and how antibiotics are prescribed in this setting. To understand these mechanisms, a realist review framework was employed. Realist reviews are exploratory by nature and aim to develop theories about the process that make interventions work by identifying 'mechanisms,

Table 1 Inclusion and exclusion criteria

\begin{tabular}{ll}
\hline Inclusion & Exclusion \\
\hline Antibiotic prescribing in primary care & $\begin{array}{l}\text { Antibiotic prescribing in secondary, tertiary care } \\
\text { services, and dentistry }\end{array}$ \\
\hline Child, adolescent, and adult health & Languages other than English \\
\hline Male and female patients & Published before 2008 \\
\hline Respiratory, ear, skin, urinary tract infections, and sepsis & All other infections \\
\hline Developed and/or used in UK & \\
\hline
\end{tabular}


Table 2 Key search terms

\begin{tabular}{|c|c|c|c|}
\hline Type of document & Search term & Alternative search terms & $\begin{array}{l}\text { Associated subjective } \\
\text { headings (MeSH terms, } \\
\text { exploded) }\end{array}$ \\
\hline - Peer-reviewed articles only & - Out of hours & $\begin{array}{l}\text { - Urgent and emergency } \\
\text { care } \\
\text { - After hours } \\
\text { - Accident and } \\
\text { emergency service }\end{array}$ & $\begin{array}{l}\text { - After-hours care } \\
\text { - Emergency medicine }\end{array}$ \\
\hline \multirow{3}{*}{$\begin{array}{l}\text { - Peer-reviewed articles } \\
\text { - Other documents (clinical } \\
\text { guidelines and training } \\
\text { materials) }\end{array}$} & - Antibiotic & $\begin{array}{l}\text { - Antibacterial } \\
\text { - Antimicrobial }\end{array}$ & - Antibacterial agents \\
\hline & - Prescription guidelines & $\begin{array}{l}\text { - Guidance on prescribing } \\
\text { - Guidance for dispensing } \\
\text { Good practice in } \\
\text { prescribing }\end{array}$ & $\begin{array}{l}\text { - Drug prescriptions } \\
\text { - Practice guidelines as } \\
\text { topic } \\
\text { - Drug utilisation } \\
\text { - Practice patterns, } \\
\text { - } \text { - Guysicians' } \\
\text { - }\end{array}$ \\
\hline & - Professional training & $\begin{array}{l}\text { - Professional } \\
\text { development } \\
\text { - Professional skills } \\
\text { - Continuing professional } \\
\text { development }\end{array}$ & $\begin{array}{l}\text { - Education, medical } \\
\text { - Education, nursing }\end{array}$ \\
\hline
\end{tabular}

contexts, and outcomes' of complex scenarios. ${ }^{16}$ Although theory generating was beyond the scope of this article, this framework guided the data synthesis towards the identification of the mechanisms underlying antibiotic prescribing.

\section{Eligibility criteria}

The authors were interested in peer-reviewed articles and grey literature concerned with how primary care professionals are trained and guided on how to prescribe antibiotics $\mathrm{OOH}$ in the UK. Training materials, clinical guidelines, reports and audits, and research articles were included. To be eligible for the review, these materials had to: be developed for the UK context or used in the UK; contain information relevant to patients of all ages and the general population; and refer to common conditions treated in primary care (see Table 1 for full inclusion and exclusion criteria). Preliminary searches (as described in the next section) identified peer-reviewed articles about antibiotic prescribing $\mathrm{OOH}$, but no guidelines and training materials designed specifically for $\mathrm{OOH}$. For this reason, the search was expanded to include any guidelines for antibiotic prescribing in primary care (either in hours or $\mathrm{OOH}$ ).

\section{Information sources}

Websites of major healthcare agencies (for example, Public Health England), websites of relevant professional associations (for example, Royal College of General Practitioners), and electronic databases (for example, MEDLINE) were searched (see Supplementary Table S1 for full list of sources used). Sources were identified based on an exploratory search of the literature, and research team and collaborators' experience.

\section{Search strategy}

The terminology used to perform the searches was informed by preliminary readings of key studies about antibiotic prescribing, as well as consultations with experts and local provider organisations (Table 2).

The search process was conducted iteratively as follows: an initial search strategy using a preliminary list of keywords was devised with librarians at the Royal Free NHS Hospital (London); a trial search was conducted to pilot the accuracy and relevance of those keywords; the list of keywords was adjusted until a final list was obtained; and finally, a second search was run where all the keywords were used in all sources and databases (see Supplementary Table S2 to access the full search strategy used). The searches were conducted in two stages: between July and October 2018 and then updated in March 2020, using the same sources and keywords. 


\section{Selection of sources of evidence}

The search results were saved and managed using EndNote (version 9). Documents were initially screened for inclusion based on title and abstract (if any) and table of contents or index. Whenever necessary the full text was consulted. All documents that met the inclusion criteria were selected. One author led the selection process with two other authors leading an independent $10 \%$ reference review for quality assurance.

The preliminary list of selected documents was circulated to the full research team and collaborators to ensure all key references were included, which resulted in the identification of additional documents. This list was also shared with two $\mathrm{OOH}$ service providers (OPEN Project partners) so that local guidelines and training materials could be identified and included in the search. The search ended in April 2020.

The heterogeneity of document formats included for review hindered the use of standardised and structured quality appraisal checklists. However, the relevance and quality of the documents considered for inclusion was discussed and agreed within the research team, which included healthcare researchers and primary healthcare practitioners.

\section{Data extraction and synthesis}

The process began by reading the full text of selected documents. Descriptive data, such as target population and year of publication, were compiled in a data extraction form, which served as a 'template to interrogate the papers'. ${ }^{17}$ Data extraction was done iteratively, with new categories being included whenever required.

The data synthesis aimed to consolidate the authors' understanding of what is known about training and clinical recommendations for antibiotic prescribing in $\mathrm{OOH}$ primary care services. Data were synthesised as follows:

\section{Contexts}

Research articles and clinical guidelines provided information about where healthcare professionals can find training and clinical guidelines for antibiotic prescribing. For this, the information regarding the year of publication, country, setting, study design, clinical condition, and clinical population was summarised for each document, and a descriptive analysis of these data was conducted, based on counts and frequencies.

\section{Mechanisms}

Clinical guidelines provided information about the type of recommendations (mechanisms) healthcare professionals are provided with to prescribe antibiotics $\mathrm{OOH}$. For this, verbatim quotations were extracted from guidelines and these data were synthesised using a qualitative meta synthesis approach: ${ }^{18}$

1. gaining familiarity with data by actively reading each document, which meant appraising and extracting the relevant information;

2. coding the information, which represented key principles for antibiotic prescribing; and

3. grouping the final codes into themes and organisation of themes into a hierarchical structure.

\section{Outcomes}

Research articles provided information about the outcomes of studies in which health professionals were provided with training or clinical guidelines about how to prescribe antibiotics $\mathrm{OOH}$. The results of each study were summarised and the key findings synthesised.

\section{Results}

\section{Search results}

The searches yielded a combined total of 2649 documents potentially eligible for review. After removing duplicates and preliminary screenings, 657 (25\%) were included in the full-text screening. Of these, 59 ( $2 \%$ of initial yield) were included for review (see Figure 1). This comprised: five peerreviewed articles, 46 clinical guidelines, and eight sets of training materials (webinars and eLearning 


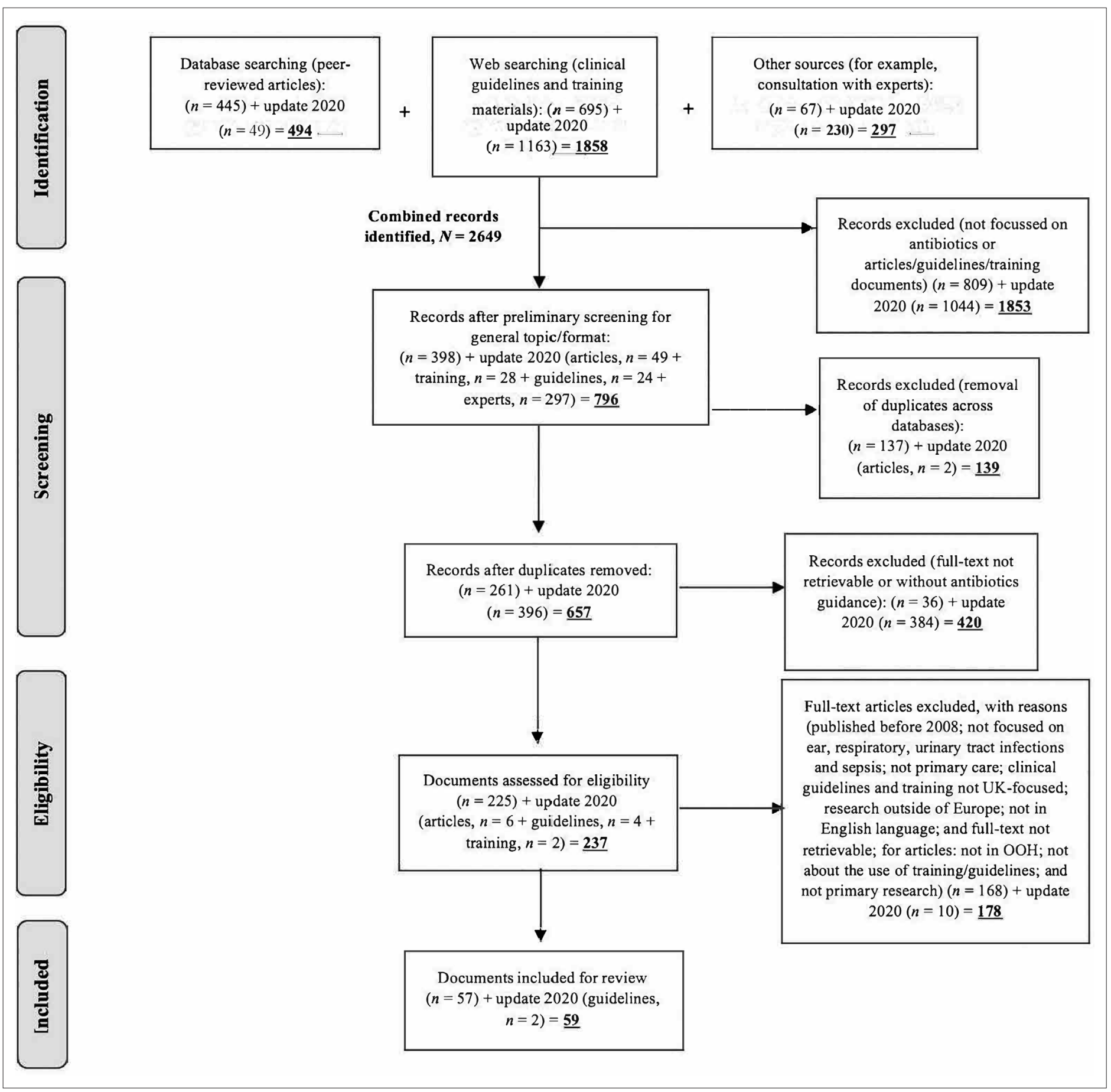

Figure 1 Selection flowchart and reasons for exclusion

modules). The research team agreed that all selected documents were relevant and of sufficient quality to inform the topic under review.

\section{What is addressed in guidance for antibiotic prescribing?}

After screening, five peer-reviewed articles were identified, of which two targeted only children and three targeted both adult and child patients. All five articles focused on in-hours care and GPs, but one also included pharmacists and a further one included nurses. Two of the articles focused on fever and one on RTIs. Two articles did not specify any health condition (see Supplementary Table S3). 
Guidelines and training materials were not specific to $\mathrm{OOH}$, but instead included guidance available to all prescribers in general practices and hospitals (see Supplementary Table S4). Guidelines fell into three categories: adults, children, and generic. Most guidelines were either non-specific or about RTIs, urinary tract infections, or sepsis. Most guidance targeted the UK only, with the remainders being international but used in the UK.

\section{Which clinical recommendations for antibiotic prescribing are being provided to primary care professionals?}

Although not specific to $\mathrm{OOH}$, clinical guidelines and training materials included a wide range of general recommendations for antibiotic prescribing (see Supplementary Table S4). The themes covered in these documents were grouped as follows: 1) spectrum of the antibiotic prescribed, that is, range of bacterial types that the antibiotic affects, including broad and narrow spectrum; 2) strategy to prescribe antibiotics, that is, immediate, no antibiotic, and delayed or 'just in case'; 3) communication with patients, that is, information and advice about antibiotics; 4) treatment duration, that is, length of prescribed antibiotic course; 5) clinical benchmarking, that is, comparisons using clinical data to support and implement best practice; and 6) decision-making process, that is, steps involved in the process leading to antibiotic prescribing, including a no antibiotic decision.

The recommendations found across the literature were consensual, and no conflicting principles were identified. Moreover, half of the clinical recommendations synthesised (see Supplementary Table S4) were endorsed by $>1$ organisation. Approximately one-third of the recommendations were published both in UK-only guidance and international documents. Just over $60 \%$ of recommendations were either revised or published in the past 2 years.

\section{How do training and guidelines impact on antibiotic prescribing $\mathrm{OOH}$ ?}

There was limited mention in the literature about the outcomes of training interventions on antibiotic prescribing in $\mathrm{OOH}$. The articles identified indicated that prescribers working $\mathrm{OOH}$ may face uncertainties about diagnosis, ${ }^{19}$ and that guidelines specifically related to working in $\mathrm{OOH}$ would be helpful in relation to the decision-making process. ${ }^{20}$ The literature also suggested that GPs and prescribing nurses may be prescribing antibiotics in $\mathrm{OOH}$ settings according to different standards and guidelines, and would appreciate supervision, discussion with peers, or clinical audits. ${ }^{21}$ Prescribing is likely to be reduced when family physicians have access to interactive booklets to facilitate communication with patients, ${ }^{22}$ and peer education programmes promote greater adherence to clinical guidelines. ${ }^{23}$ See Supplementary Table S3 for further details concerning the findings of the studies.

\section{Discussion}

\section{Summary}

The goal of this study was to explore the existing clinical recommendations for primary care professionals working $\mathrm{OOH}$, regarding how and when to prescribe antibiotics. A realist-informed review was conducted to provide an overview of the contexts, mechanisms, and outcomes of these recommendations, described both in guidelines available to primary care professionals and research in the field.

The key finding is that there is a paucity of information about how professionals are being trained to prescribe antibiotics specifically in $\mathrm{OOH}$ and whether further, specific training is required. For instance, guidelines that were reviewed highlight that professionals should discuss treatment plans, manage expectations, and inform patients about the consequences of antibiotics and self-limiting conditions. However, there is a dearth of evidence regarding the basis for these recommendations, how they are being implemented in $\mathrm{OOH}$ settings, or indeed how appropriate they are for this context, where healthcare professionals often have to diagnose infection without access to laboratory results. Additionally, it is also clear that further empirical research is needed in this field, particularly in relation to whether training professionals in $\mathrm{OOH}$ contributes to lower prescribing rates. 


\section{Strengths and limitations}

The primary limitation of this review was the lack of information about training materials and guidelines focusing on $\mathrm{OOH}$ contexts. The search results were shared with two $\mathrm{OOH}$ service providers in the hopes of identifying further resources; however, no additional materials were identified. This made it difficult to produce definitive conclusions, aside from that professionals in $\mathrm{OOH}$ may not have access to specific training related to working in this context. Future studies should aim to engage with further $\mathrm{OOH}$ providers to ensure that local guidance is also considered. Nevertheless, the realist-informed review allowed the mechanisms underlying antibiotic prescribing in $\mathrm{OOH}$ to be considered, which may provide a platform on which to build future theoretical work. Another limitation is that owing to the heterogeneity of sources, quality assurance review was dependent on the expertise and judgement of the research team, as opposed to traditional standardised quality appraisal procedures.

\section{Comparison with existing literature}

The limited research on prescribing antibiotics in $\mathrm{OOH}$ settings makes it difficult to compare the findings with previous literature. Previous studies have shown that educational interventions and training are likely to optimise prescribing competency ${ }^{24}$ and reduce inappropriate prescribing. ${ }^{25}$ The literature also indicates that general training for GPs and other clinicians working $\mathrm{OOH}$ could be expanded and standardised at national level. For instance, in a survey with over 1000 GP trainees in England, Hayward et a ${ }^{26}$ found that only half of GP trainees received formal education sessions on $\mathrm{OOH}$ care, and no more than one-third were offered formal training in $\mathrm{OOH}$ home visits. Training in $\mathrm{OOH}$ care is generally perceived as a positive experience for GPs and trainees, suggesting that further training could be well received. ${ }^{27}$

\section{Implications for research and practice}

This review highlights the need for further thought and discussion as to whether general clinical guidelines on antibiotic prescribing are adequately addressing the particularities and challenges of $\mathrm{OOH}$ care. This includes: 1) the management of patients by health professionals unfamiliar with their medical history; 2) limited access to medical records and testing; 3 ) higher levels of patient (and caregiver) pressure and patient anxiety; 4) perceived or actual urgency of complaints or acuity of infections on point; 5) patients who may have experienced difficulties accessing care and prescriptions in hours; and 6) little opportunity for patient follow-up. ${ }^{14,21,28}$ It is important to explore the needs of healthcare professionals working $\mathrm{OOH}$ and their preferences regarding the format and type of resources needed to support this work to ensure that the success of future interventions is optimised.

In terms of prescribing strategies, the review identified various recommendations for UK healthcare professionals when prescribing antibiotics. However, since none of these were tailored specifically to $\mathrm{OOH}$ care, it is uncertain whether the recommendations are relevant and feasible in this setting. For instance, research shows that delayed prescribing has been associated with a decrease in antibiotic use. ${ }^{29-33}$ Further research is needed to explore the benefits and barriers to offering delayed antibiotic prescriptions $\mathrm{OOH}$ where there may be particular patient expectations regarding the immediacy of the need for a prescription.

Moreover, as Colliers et a ${ }^{20}$ suggest, based on primary care in Belgium, GPs working $\mathrm{OOH}$ do not always feel confident in their decision making regarding antibiotics and feel less responsible for these decisions owing to patients being 'unknown'. Similar findings were reported in the UK, where research highlighted the lack of prior relationship with patients as a factor hindering clinical decision making. ${ }^{21}$ On this basis, the authors believe that evidence-based training may help strengthen antibiotic stewardship practices in $\mathrm{OOH}$ contexts. Evidence-based targeted training may result in modifying $\mathrm{OOH}$ consulting behaviour and optimising prescribing practices in line with generalised antibiotic stewardship programmes, which have been shown to be effective in improving patient outcomes, producing savings for health services, and reducing antibiotic resistance. ${ }^{33}$

This review identified no current clinical guidelines or training resources focusing on antibiotic prescribing targeting professionals working in $\mathrm{OOH}$ primary care settings in the UK. In addition, it identified only limited research evidence about the use of educational interventions in this field. The review also suggests that even though they have been separated from in-hours GP services since 2004 , it is unclear which guidelines are being used by medical and non-medical prescribers working $\mathrm{OOH}$ in the UK. 
Further research is needed to ascertain whether the existing guidance is fit for the challenges faced in $\mathrm{OOH}$ settings, and whether and what other resources targeting antibiotic prescribing $\mathrm{OOH}$ need to be developed. Observational and exploratory research could be a first step towards understanding the context and training needs of professionals working $\mathrm{OOH}$, and how training and updated guidelines could best support prescribing practices.

\section{Funding}

This research was funded by the National Institute for Health Research (NIHR) School for Primary Care Research (project number: 414) using aid from the UK government to support primary care research. The views expressed in this publication are those of the author(s) and not necessarily those of the NIHR or the Department of Health and Social Care.

\section{Ethical approval}

This literature review focused on publicly available documents and did not include any primary research. Therefore, no institutional ethical approval was required.

\section{Provenance}

Freely submitted; externally peer reviewed.

\section{Acknowledgements}

The authors would like to express their gratitude to the MSc Psychology student who was funded by the Institute for Lifecourse Development (University of Greenwich) to assist the team with updating the literature search.

\section{References}

1. Ventola CL. The antibiotic resistance crisis: part 1: causes and threats. P T 2015; 40(4): 277-283.

2. Public Health England. English surveillance programme for antimicrobial utilisation and resistance (ESPAUR): report 2017. 2017; https://webarchive.nationalarchives.gov.uk/20191003132022/https://www.gov.uk/government/ publications/english-surveillance-programme-antimicrobial-utilisation-and-resistance-espaur-report (accessed $8 \mathrm{Apr}$ 2021).

3. Public Health England. English surveillance programme for antimicrobial utilisation and resistance (ESPAUR): report 2019 to 2020. 2020; https://assets.publishing.service.gov.uk/government/uploads/system/uploads/attachment_ data/file/843129/English_Surveillance_Programme_for_Antimicrobial_Utilisation_and_Resistance_2019.pdf (accessed 8 Apr 2021).

4. Hayward GN, Fisher RFR, Spence GT, Lasserson DS. Increase in antibiotic prescriptions in out-of-hours primary care in contrast to in-hours primary care prescriptions: service evaluation in a population of 600000 patients. J Antimicrob Chemother 2016; 71(9): 2612-2619. DOI: https://doi.org/10.1093/jac/dkw189

5. European Centre for Disease Prevention and Control. Rates by country. 2021; https://www.ecdc.europa.eu/en/ antimicrobial-consumption/database/rates-country (accessed 8 Apr 2021).

6. Pouwels KB, Dolk FCK, Smith DRM, et al. Explaining variation in antibiotic prescribing between general practices in the UK. J Antimicrob Chemother 2018; 73(suppl_2): ii27-ii35. DOI: https://doi.org/10.1093/jac/dkx501

7. Smieszek T, Pouwels KB, Dolk FCK, et al. Potential for reducing inappropriate antibiotic prescribing in English primary care. J Antimicrob Chemother 2018; 73(suppl_2): ii36-ii43. DOI: https://doi.org/10.1093/jac/dkx500

8. Gulliford MC, Moore MV, Little $P$, et al. Safety of reduced antibiotic prescribing for self limiting respiratory tract infections in primary care: cohort study using electronic health records. BMJ 2016; 354: i3410. DOI: https://doi.org/ 10.1136/bmj.i3410

9. Garzonis K, Mann E, Wyrzykowska A, Kanellakis P. Improving patient outcomes: effectively training healthcare staff in psychological practice skills: a mixed systematic literature review. Eur J Psychol 2015; 11(3): 535-556. DOI: https://doi.org/10.5964/ejop.v11i3.923

10. Little $\mathrm{P}$, Stuart $\mathrm{B}$, Francis $\mathrm{N}$, et al. Effects of internet-based training on antibiotic prescribing rates for acute respiratory-tract infections: a multinational, cluster, randomised, factorial, controlled trial. Lancet 2013; 382(9899): 1175-1182. DOI: https://doi.org/10.1016/S0140-6736(13)60994-0

11. Cals JWL, Butler CC, Hopstaken RM, et al. Effect of point of care testing for $C$ reactive protein and training in communication skills on antibiotic use in lower respiratory tract infections: cluster randomised trial. BMJ 2009; 338: b1374. DOI: https://doi.org/10.1136/bmj.b1374

12. Dekker ARJ, Verheij TJM, Broekhuizen BDL, et al. Effectiveness of general practitioner online training and an information booklet for parents on antibiotic prescribing for children with respiratory tract infection in primary care: a cluster randomized controlled trial. J Antimicrob Chemother 2018; 73(5): 1416-1422. DOI: https://doi.org/10. 1093/jac/dkx542 
13. Kronman MP, Gerber JS, Grundmeier RW, et al. Reducing antibiotic prescribing in primary care for respiratory illness. Pediatrics 2020; 146(3): e20200038. DOI: https://doi.org/10.1542/peds.2020-0038

14. Giesen $P$, Smits $M$, Huibers $L$, et al. Quality of after-hours primary care in the Netherlands: a narrative review. Ann Intern Med 2011; 155(2): 108-113. DOI: https://doi.org/10.7326/0003-4819-155-2-201107190-00006

15. Tricco AC, Lillie E, Zarin W, et al. PRISMA extension for scoping reviews (PRISMA-ScR): checklist and explanation. Ann Intern Med 2018; 169(7): 467-473. DOI: https://doi.org/10.7326/M18-0850

16. Pawson R, Greenhalgh T, Harvey G, Walshe K. Realist review - a new method of systematic review designed for complex policy interventions. J Health Serv Res Policy 2005; 10(Suppl 1): 21-34. DOI: https://doi.org/10.1258/ 1355819054308530

17. Rycroft-Malone J, McCormack B, Hutchinson AM, et al. Realist synthesis: illustrating the method for implementation research. Implement Sci 2012; 7: 33. DOI: https://doi.org/10.1186/1748-5908-7-33

18. Thomas J, Harden A. Methods for the thematic synthesis of qualitative research in systematic reviews. BMC Med Res Methodol 2008; 8: 45. DOI: https://doi.org/10.1186/1471-2288-8-45

19. de Bont EGPM, Peetoom KKB, Moser A, et al. Childhood fever: a qualitative study on GPs' experiences during outof-hours care. Fam Pract 2015; 32(4): 449-455. DOI: https://doi.org/10.1093/fampra/cmv029

20. Colliers A, Coenen S, Remmen R, et al. How do general practitioners and pharmacists experience antibiotic use in out-of-hours primary care? An exploratory qualitative interview study to inform a participatory action research project. BMJ Open 2018; 8(9): e023154. DOI: https://doi.org/10.1136/bmjopen-2018-023154

21. Williams SJ, Halls AV, Tonkin-Crine S, et al. General practitioner and nurse prescriber experiences of prescribing antibiotics for respiratory tract infections in UK primary care out-of-hours services (the UNITE study). J Antimicrob Chemother 2018; 73(3): 795-803. DOI: https://doi.org/10.1093/jac/dkx429

22. de Bont EGPM, Dinant G-J, Elshout G, et al. Booklet for childhood fever in out-of-hours primary care: a clusterrandomized controlled trial. Ann Fam Med 2018; 16(4): 314-321. DOI: https://doi.org/10.1370/afm.2265

23. Dyrkorn R, Gjelstad S, Espnes KA, Lindbæk M. Peer academic detailing on use of antibiotics in acute respiratory tract infections. A controlled study in an urban Norwegian out-of-hours service. Scand J Prim Health Care 2016; 34(2): 180-185. DOI: https://doi.org/10.3109/02813432.2016.1163035

24. Kamarudin G, Penm J, Chaar B, Moles R. Educational interventions to improve prescribing competency: a systematic review. BMJ Open 2013; 3(8): e003291. DOI: https://doi.org/10.1136/bmjopen-2013-003291

25. Santos NSD, Marengo LL, Moraes FdaS, Barberato Filho S. Interventions to reduce the prescription of inappropriate medicines in older patients. Rev Saude Publica 2019; 53: 7. DOI: https://doi.org/10.11606/S15188787.2019053000781

26. Hayward G, Drinkwater J, El-Gohary M, et al. GP training in out-of-hours care: implications for the future workforce. Educ Prim Care 2015; 26(2): 95-101. DOI: https://doi.org/10.1080/14739879.2015.11494320

27. Lewis GH, Sullivan MJ, Tanner R, et al. Exploring the perceptions of out-of-hours training for GP registrars in Wales. Educ Prim Care 2009; 20(3): 152-158. DOI: https://doi.org/10.1080/14739879.2009.11493786

28. Foster H, Moffat KR, Burns N, et al. What do we know about demand, use and outcomes in primary care out-ofhours services? A systematic scoping review of international literature. BMJ Open 2020; 10(1): e033481. DOI: https://doi.org/10.1136/bmjopen-2019-033481

29. Moore $M$, Little $P$, Rumsby $K$, et al. Effect of antibiotic prescribing strategies and an information leaflet on longerterm reconsultation for acute lower respiratory tract infection. Br J Gen Pract 2009; 59(567): 728-734. DOI: https:// doi.org/10.3399/bjgp09X472601

30. Peters S, Rowbotham S, Chisholm A, et al. Managing self-limiting respiratory tract infections: a qualitative study of the usefulness of the delayed prescribing strategy. Br J Gen Pract 2011; 61(590): e579-e589. DOI: https://doi.org/ 10.3399/bjgp11X593866

31. Raft CF, Bjerrum L, Arpi M, et al. Delayed antibiotic prescription for upper respiratory tract infections in children under primary care: physicians' views. Eur J Gen Pract 2017; 23(1): 191-196. DOI: https://doi.org/10.1080/ 13814788.2017.1347628

32. Ryves $\mathrm{R}$, Eyles $\mathrm{C}$, Moore $\mathrm{M}$, et al. Understanding the delayed prescribing of antibiotics for respiratory tract infection in primary care: a qualitative analysis. BMJ Open 2016; 6(11): e011882. DOI: https://doi.org/10.1136/ bmjopen-2016-011882

33. Srinivasan A. Antibiotic stewardship: why we must, how we can. Cleve Clin J Med 2017; 84(9): 673-679. DOI: https://doi.org/10.3949/ccjm.84gr.17003 